\title{
9-cis-Retinoic Acid/Interferon Alfa
}

National Cancer Institute

\section{Source}

National Cancer Institute. 9-cis-Retinoic Acid/Interferon Alfa. NCI Thesaurus. Code C15624.

A combination drug therapy. 